\title{
AHP, a Reliable Method for Quality Decision Making: A Case Study in Business
}

\author{
Irina Canco ${ }^{1}$, Drita Kruja ${ }^{1}(1)$ and Tiberiu Iancu ${ }^{2, *}$ \\ 1 Marketing \& Management Department, Faculty of Economy, Business and Development, \\ European University of Tirana, 1000 Tirana, Albania; irina.canco@uet.edu.al (I.C.); \\ drita.kruja@uet.edu.al (D.K.) \\ 2 Faculty of Management and Rural Tourism, Banat's University of Agricultural Sciences and Veterinary \\ Medicine "King Michael I of Romania", Calea Aradului No. 119, 300645 Timisoara, Romania \\ * Correspondence: tiberiuiancu@usab-tm.ro
}

check for updates

Citation: Canco, I.; Kruja, D.; Iancu, T. AHP, a Reliable Method for Quality Decision Making: A Case Study in Business. Sustainability 2021, 13, 13932. https://doi.org/10.3390/ su132413932

Academic Editors: Alex Opoku and Jeoung Yul Lee

Received: 30 October 2021

Accepted: 10 December 2021

Published: 16 December 2021

Publisher's Note: MDPI stays neutral with regard to jurisdictional claims in published maps and institutional affiliations.

Copyright: (c) 2021 by the authors. Licensee MDPI, Basel, Switzerland. This article is an open access article distributed under the terms and conditions of the Creative Commons Attribution (CC BY) license (https:/ / creativecommons.org/licenses/by/ $4.0 /)$.

\begin{abstract}
Decision making is a significant responsibility for business managers, their decisions impacting business performance. Managers are therefore interested in acquiring and implementing reliable methods for making decisions both now and in the future. Currently, in the countries in the Albanian-speaking regions of the Western Balkans, intuitive decision-making methods predominate. In order to find appropriate methods for assessing and prioritizing goals, new approaches to decision making should be adopted. Various methods have been developed for multi-criteria decision making. One of these is the Analytic Hierarchy Process (AHP) method-a method which should receive more attention than it has up to now. We would like to show that the AHP method could be of great use in decision making. Through a case study, this paper explores the AHP, a method with three levels in which the identification of decision-making criteria is based on the perceptions of managers and consumers. The paper's findings offer an important guide for managers to improve decision making and enhance performance in competitive markets.
\end{abstract}

Keywords: Analytic Hierarchy Process (AHP); pairwise comparison; decision making; the relative importance of criteria; the importance weightings of criteria; Albanian-speaking regions

\section{Introduction}

Decision making involves many different complex and difficult economic problems, the factors involved acting independently or coordinately, at the same time or at different times. These factors are reflected in the methods of decision making, the purpose of which is to support and enhance the quality of decision making at managerial levels.

The methods applied in decision making vary over time in relation to goals, situations and expected results. This evolution of decision-making methods is a direct reflection of social, economic and scientific developments especially. The development of science presents the most important factor in the evolution of decision-making methods, research into which continues unabated.

Decision-making methods fall into two different groups: intuitive methods and analytical methods [1-4]. The difference between them is wide and basic [3]. These differences need to be considered by managers in their commitment to effective decision making.

Analytical methods in decision making positively influence business performance. Decisions based on these methods are supposed to generate income with limited resources. Focusing on strategic decisions highlieghted: "Such a demanding strategic decision is also a decision on the composition of the optimum project portfolio with limited company resource availability" [5]. While Kliestik et al. [6], referring to Schipper (1989), have emphasized that "The importance of earnings management was underlined by Schipper (1989) whose research focused on three issues: defining the object of earnings management, exploring conditions giving rise to earnings management and designing of empirical 
tests". Valaskova et al. [7] drawing on the work Bin et al. (2018), maintain that earnings management is a sound and legal way of managing and reporting business activities aimed at achieving stable and predictable financial results.

Practically, decision making has an impact on a variety of factors that in some cases come into conflict with each other. This complicates a manager's decision making, especially when the decisions are critical for the future of the business. Decision-making problems are of different sorts, presenting different challenges; there may be more than one solution to a problem, or a number of criteria in relation to which the alternative solutions have to be evaluated, or a number of alternative possible future scenarios in which different solutions would be optimal. It is this complexity that necessitates an extended evaluation phase in decision problems [1]. The manager also faces complex decisions-decisions which, as a rule, involve several people and many variables, for which various criteria need to be into account to solve them, some of which may not be quantifiable but are important, or may be important at a later time [8]. Frequently, the decision-making process is guided by experience. While some scholars admit that making decisions based on experience is common in, for instance, Egyptian manufacturing firms, there is uncertainty in the process related to the size of the company, the risk factors increasing the consequentiality of the decision, environmental hostility giving rise to an interplay between intuition and disturbance [9] argue that the empirical examination of intuition has an importance role in effective decision making. Thus, the commitment of the science-oriented manager to various sources, such as informatics, statistics, mathematics, etc., enables decision making based on more reasonable and argumentative analysis.

This scientific paper does not address the totality of decision-making problems. Therefore, the main objective is to analyze specific issues in decision making and to suggest new applications of decision-making procedures in actual conditions. To achieve this objective, we have focused on the research question: What methods should be used to collect and analyze individual judgments in decision making?

Based on the above, we have set out to prove the hypothesis that the AHP enables the selection of the best of a range of alternative solutions in the context of decision making based on individual judgments.

The study is significant in that it focuses in an analytical manner on decision making based on the AHP - a method that can be used in actual conditions in regional countries to ensuring success in business.

\section{Literature Review}

Decision making is an activity that has a fairly large scope and impact on business performance. The ability to make decisions is an attribute of the human species, the exercise of which engages individuals throughout their lives [10]. Decisions are ubiquitous, affecting innumerable aspects of our lives. There are decisions for our families, our children, clients, employers, stockholders, patients, students, elderly parents, club members, and so on [11]. Knowledge about decision making requires flexibility-something which is readily appreciable in business and professional contexts, but is necessary when it comes to making any decision, whether it is a personal decision, a family decisions, and so forth [12]. From the totality of options the manager must distinguish the optimum decision [10]. The performance of businesses creates an ever-growing need for scientific knowledge. However, the quality of a decision is based on the power of the decision-making abilities in question [13]. An optimum decision presupposes two dimensions: a temporal dimension and a qualitative dimension. In this context, decision making represents a process that is subject to planning. Planning can help to define independent goals, provide standards of measurement, transform values to actions and determine the effective use of resources [14].

Lack of planning in decision making reduces effectiveness and generally leads to questionable conclusions. Planning in decision making is easier than it appears [15] and involves an appreciation of the "time" dimension in particular. 
The consequences of a decision are conditioned, also, by the time available. Decision making often requires discussions, which take time. Decision-making bodies need to know when to end deliberations, which is tricky. Deciding to end the process too early is as damaging as deciding to end it too late. "Time" defines the first out of six influential factors in decision making; the availability of time - "the time available to make the decision" [16] - must be precisely determined. Consideration of time in decision making excludes limiting failures.

Time is presented as a limiting factor in two directions. First, from the point of view of its presence in each stage of decision making; and, secondly, from the point of view of the ability of the manager to devote sufficient time to each stage of the decision-making process.

Decision making is permanently present in business. As such, in many cases, the manager has to make decisions in a short time, even in a chaotic environment. Decision making in such situations has been understood in terms of a "Garbage Can Model of Organizational Choice" [17]. Based on this model, the decision-making process can be presented schematically as follows (Figure 1):

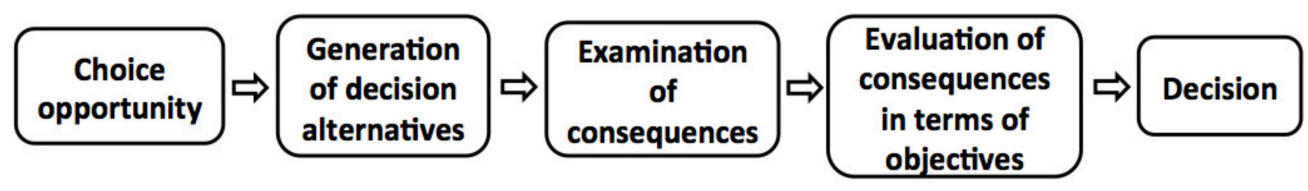

Figure 1. Schematic representation of the decision-making process.

This environment has been called an "anarchic environment" [18]. Regarding the above, "the choice opportunities" are recognized with the generation of decision alternatives, the process continues with an examination of their consequences, then moves on to an evaluation of consequences in the context of objectives, and finally to a decision. This is an overly simplistic description compared to what actually happens [17].

Other scholars, in later periods, have found problems with the original article by Cohen et al. [17] on the Garbage Can Model. Specifically, the program created by Cohen et al. [17] failed to detect "three decision-making styles" (decision by resolution, decision by oversight and decision by flight) [19]. Also important in decision-making theory are Simon's theories on limited rationality. There are important restrictions on cognition that condition human behavior, specifically: "(i) incompleteness of information; (ii) difficulty in the anticipation of the consequences; and (iii) scarce knowledge of all possible human behaviors" [20].

Generally, decision making in regional countries is a routine activity post-totalitarianism. The culture of doing business is influenced by the national culture. The decision-making methods in centralized business cultures are based on manager experience-that is, they are intuitive methods. Business managers are inclined to be guided by them [21].

Intuition appears as a non-sequential information-processing mode [22]. As such, intuition has various limitations. It is a process of combining expertise and know-how with an employee's instincts rather than just a series of random guesses [23]. As a consequence of relying on intuitive methods, managers have not infrequently found themselves at a crossroads. More than ever, managers are required to change their approach to decision making by focusing on analytical methods. such as statistical, econometric and mathematical methods. Decision making, for which we gather large amounts of information, has "become a mathematical science today" [24]. The mathematical methods in decision making provide fast, accurate and safe solutions. The quality of a decision is also conditioned by the use of mathematical methods. Therefore, some scholars have stressed that the making of optimum decisions equates to "the mathematical optimization problem" [25].

Since there are numerous mathematical methods, the manager must adapt the methods to the problem that the decision is about.

Decision theory represents a multidisciplinary theory that uses different methods to guarantee the quality of a decision. One of the recommended methods is the Analytic 
Hierarchy Process (AHP). This is the method will be used in this paper. AHP guarantees quality because it has a powerful mathematical base and is to be used in the process of the evaluation and selection of alternatives [26]. Many scholars are engaged in the use of the AHP method. According to Emrouznejad and Marra [27], "the number of publications related to the topic of AHP has increased over the last 10 years, ... — more than 800 published works-in 2013 and 2015".

AHP has been used in various domains-business, government, military and industrial [28]. It has an overall value for each country, but developing countries need to use AHP for the evaluation and solution of complex economic problems from different perspectives of development [29]. The AHP method helps decision makers find the best answer [30]. The benefit of this method (AHP) based on experience, intuition and also on physical data, is that it may deal with qualitative as well as quantitative aspects of a decision-making problem [31].

Highlighted that AHP has a number of advantages, including [32]:

i Its usability;

ii It is an effortlessly reasonable system;

iii It disentangles a troublesome issue by separating it into smaller steps;

iv It does not require authentic information sets.

Over the years, AHP has evidenced a number of disadvantages, which have been studied by numerous researchers. According to Munier and Hontoria [33], Salvia et al. (2019), referring to other researchers, stressed that some of the disadvantages of this method (AHP) include the high computational requirement even for small problems, as well as its subjective nature and the fact that it relies on emotions being translated into numerical judgments, while the increased time and effort it involves demands larger numbers of pair comparisons [32]. Another disadvantage is the fact that criteria may change their value in space and time, so that pairwise comparison is the worst method for weighting [33]. Again, based on Munier and Hontoria [33], Asadabadi et al. (2018) have highlighted that "It is a mathematically proven fact that when the order of a matrix increases to more than three, the inconsistency issue arises and increases exponentially as the number of the criteria and alternatives grows. If CR is more than 0.1 , the user is blamed for providing inconsistent comparisons ... ... ". According to Jimenez et al. [34] "One of the weakest points of AHP is the difficulty in working with large problems, that is, with problems with many hierarchy levels (above 4)". However, using the AHP method in decision making should not be avoided outright because, as Munier and Hontoria [33], referring to Barakos (2019), have noted, "AHP is not fawless but can be a very powerful tool if you can use it properly". "AHP is not a mathematically rigorous method developed by Saaty" [33]. Song and Kang [35] stressed, however, that "the AHP has various weaknesses including ambiguous questions, fixed measurement scales, and varied results, depending on the form of hierarchy structure despite the attributes themselves being unchanged".

Despite the disadvantages, using the AHP method in decision making is crucial because, according to Kazibudzki [36], "Intuitive decisions are not supported by data and documentation and may appear arbitrary".

Decision making according to AHP is both a wide and complex process because AHP can be used for decision making in both the physical and social domains [37]. Furthermore, AHP is a "hierarchical model of decision making" in that it descends from a focus, down to criteria, down further to subdivisions of the criteria and finally to the alternatives [26]. The most frequently used method is data envelopment analysis and the most popular integrated method is analytical hierarchy "process-goal programming" [38]. AHP decision making consists of three levels: the goal, the criteria which form the second level and the different alternatives at the third level of hierarchy [29].

The influencing factors were named criteria. Russo and Camanho [39] referring to other researchers, emphasized that "In general, the influence factors are denominated criteria. However, they also were called aspects-Huang, Chu, Chiang (2008) and Hsu, Lee, Kreng (2010), attributes-Hsu, Lee, Kreng (2010), classes-Rezaei, Fahim PBM, Tavasszy 
(2014), dimensions-Chiang; Yang, Chuang (2009) and Rostamzadeh (2011), families- Vidal, Marle, Bocquet (2011), index-Benter, Carneiro, da Silva, Kimuro (2010) and perspectivesHuang, Chu, Chiang (2008)". Decision making based on AHP involves many criteria and subcriteria for ranking the alternatives to be selected from [40].

Decision making cannot be general but is dependent on the problem in question. In the decision-making process, to achieve the goal and objectives, the first step is to choose the appropriate decision-making method that fits the problem type [41]. Range of potential methods will be used is partly conditioned by their treatment in the literature. Whether a method can be used is a matter requiring evidence derived from a specific case. In this context, it is important that empirical methods be used to investigate contemporary related phenomena to gain an in-depth understanding of the actual factors in play [42].

\section{Materials and Methods}

To undertake this scientific work, scientometrics has been used. A study was conducted of a company that operates in Albania from the perspective of the countries of the region. The study used both primary and secondary data. The collection of secondary data is made possible through prestigious publications and various scientific articles. We carried out interviews to collect data from the parties of interest. The aim is to cover the current situation and to predict the problems that might be encountered in the future.

Data processing considers the Analytic Hierarchy Process (AHP). The importance of AHP lies in the fact that it helps decision makers to transform subjective judgments into objective measures [43]. However, AHP has a specific approach, developed in the 1970s, to give decision making based on experience, intuition and heuristics the structure of a well-defined methodology derived from sound mathematical principles [44]. In addition, the model supports a pairwise comparison approach to characterize the relative importance of the performance criteria and assign importance weightings to them.

Evaluation of the interview responses according to the double comparison of criteria was performed using a nine-point scale. The AHP was used to develop comparative matrices in the pair derived from interview estimates.

We provide a case study, as many scholars recommend, the intensive study of a single unit or a small number of units enabling understanding of a larger class of similar units [45]. Yin [46] highlighted that "The ability to address the complexity and contextual conditions nevertheless establishes case study methods as a viable alternative among the other methodological choices, such as survey, experimental, or economic research". The goal is the quality of the case study. The goal is to design good case studies and collect, present, analyze and report data in a fair way [42,47]. Murphy [48] describes this strength by saying that case studies as a research method are non-prejudicial.

The object of the study is a company located in Tirana. The choice of this company was made in collaboration with the company management team in order to support the company and improve market performance in the future.

Findings: The findings of this paper provide important and concrete information on managerial decision making in Albania. They reflect the development trends of decision making, and from this perspective a new, modern approach has been taken into consideration - an approach which, importantly, is completely unknown in the region. Specifically, the findings show that the largest global weight corresponds to the alternative beer "Beer 1". "Beer 1" is the best among competing alternatives-this is what the business must claim in order to launch in the market. In perspective, the findings will enable managers to successfully develop decision making in order to enhance strategic business management with respect to customer requirements.

Limitations: The first limitation of this paper concerns the fact that the estimations of beer characteristics based on clients opinion are considered individual perceptions, based on their personal preferences.

The second limitation is that the study was conducted for a separate business. 


\section{Results}

This case study addresses important issues in business decision making, including the application of procedures, associated processes and reference solutions. A case study is one case, or a small number of cases, for which scores are obtained from close observation of the actual circumstances and analyzed in a qualitative manner [49]. In this paper, to develop the case study, the stages proposed by Saaty in the different years (1980, 1990, 2000, 2005) for using the AHP method were followed [50]. It is important that the structuring phase is based on obtaining the decision-making model presented in the form of a hierarchy in the AHP [51]. There are three main phases in the AHP model: "structuring the problem, comparative judgments, and priority analysis" [50].

In this context, the decision making in the company S. \& Co. was analyzed according to AHP. The company was founded in 1994. It has generally been a successful business for a long time. Several companies already operate in this market so that it is highly competitive. According to the available data, the quantity of units sold by S. \& Co over a period of 4 years (2017-2020) turns out to have decrease from $267.000 \mathrm{Hl}$ (2017) to $241.000 \mathrm{Hl}$ (2020) based on the Figure 2 as follows:

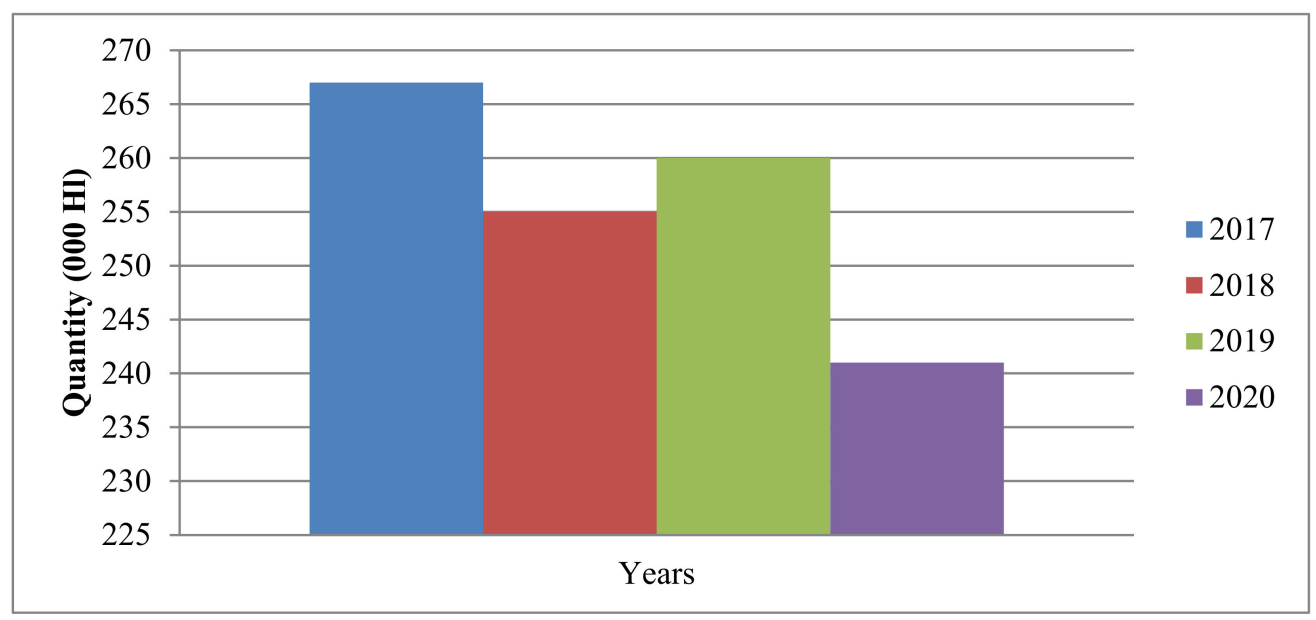

Figure 2. The decision making according to AHP-results presented at company S. \& Co.

The market share of this company was therefore under constant threat. In this situation, the staff of S. \& Co raised the claim that in the context of increasing market share, the company had to emphasize in the launch of a new beer its improved quality compared to existing alternative brands. This meant that an important decision had to be made. Considering the focus of this decision, the best way is to engage in decision making according to AHP.

The use of the model helped to analyze the decision before making the final choice [52]. For this, the staff of S. \& Co were asked together the information needed to make a decision based on the AHP method. This method puts the decision maker's preference in the first place and helps to select a method for their decision making [53]. The AHP approach is a subjective methodology; information and the priority weights of elements may be obtained from a decision maker of the company using direct questioning or a questionnaire method [54]. Additionally, AHP was used to select energy alternatives [55].

The marketing department was asked to prepare three alternative beer by labeling them in this preliminary stage "S . . 1" $\left(\mathrm{M}_{1}\right)$, "S . . 2" $\left(\mathrm{M}_{2}\right)$ and "S . . 3" $\left(\mathrm{M}_{3}\right)$. The differences between them focused mainly on three characteristics:

- $\quad \mathrm{K}_{1}$-Production cost

- $\mathrm{K}_{2}$-Taste

- $\mathrm{K}_{3}$-Consistency

The choice between the three alternatives, if it was to be made by the managers based solely on their personal experience, would be associated with many problems and would 
call into question their business performance. This reinforces the idea that, for a more successful choice, the AHP should be used, the AHP, as has already been noted, being one of the most widely used multiple-criteria decision-making tools [29] and a method that is both easy to use and flexible [56].

Priorities hierarchy of three criterion $\left(\mathrm{K}_{1}, \mathrm{~K}_{2}, \mathrm{~K}_{3}\right)$ for three beer alternative and relevant decision making based on the AHP method developed by Saaty (1970 is represented in the Figure 3 below:

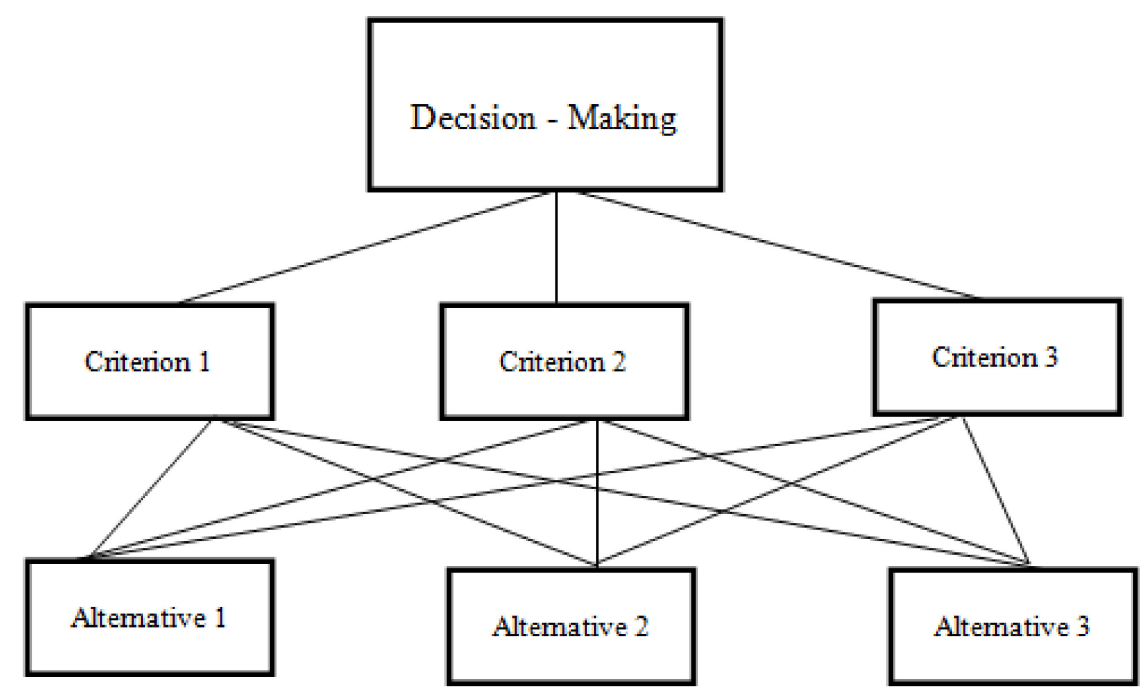

Figure 3. Decision making according to the AHP method.

In this context, AHP considers a scale of measurement with three elements and four phases. The elements of scale of measurement are: a set of objects, a set of numbers and a mapping of objects to numbers [57]. The phases are: structuring the problem to build up the hierarchy, collecting data through pairwise comparison, determining the priorities and performing an analysis for the solution of the problem [37].

Decision making is considered a comparative consideration by decision makers of the range of alternatives and criteria. Comparative criteria are generally of different natures. Returning to a single unit is an important problem in multi-criteria analysis. The use of quantitative "equivalents" of comparative expressions is crucial. Their ratings are made based on rating scale prepared by Saaty [37], which provides a means of marking numerically the relative importance of the elements. The fundamental problem for AHP is pairwise comparison. The pairwise comparison considers these problems: (i) that every subcriterion be taken into account for each alternative, (ii) that the main criterion be taken into account for each subcriterion and (iii) that the goal be taken into account for each of the main criteria [58]. In this context, AHP seeks rigorous implementation of the scaling problem, using the sorting of numbers to correctly combine the priorities resulting from them [57].

Saaty [40], in a discussion of pairwise comparisons, admits that the Analytic Hierarchy Process is based on the measurement of pairwise comparisons and therefore needs the judgments of experts to derive priority scales. Some scholars maintain that the pairwise comparisons classify two elements: A and B. The comparisons take the form of presenting element A as being more important than element B [54]. Therefore, it is necessary to measure them. In this context, a scaling method based on hierarchical structures has been held to be necessary [59], whereas Cristobal and Ramon [60], referring to Saaty (1977), propose to use his suggestion about a numerical scale (0-9) to transform qualitative data into quantitative data, where 1 is evidence of equal importance and 9 is evidence of a situation with extreme importance.

Saaty [61] suggested that the relative significance scale predicts values from 1 to 9 and presented it as follows (Table 1): 
Table 1. The relative significance scale suggested by Saaty.

\begin{tabular}{ccc}
\hline Scale & Numerical Rating & Reciprocal \\
\hline Extremely Preferred & 9 & $1 / 9$ \\
Very strong to extremely & 8 & $1 / 8$ \\
Very strong preferred & 7 & $1 / 7$ \\
Strongly to very strongly & 6 & $1 / 6$ \\
Strongly preferred & 5 & $1 / 5$ \\
Moderately to strongly & 4 & $1 / 4$ \\
Moderately preferred & 3 & $1 / 3$ \\
Equally to moderately & 2 & $1 / 2$ \\
Equally preferred & 1 & 1 \\
\hline
\end{tabular}

$\checkmark \quad$ Local weights related to criterion 1

The Analytic Hierarchy Process enables each alternative to be evaluated based on the importance of one alternative over another by reference to a common factor [62]. The comparison matrix has been designed in support of expert assessments. Priority determination is an advantage of AHP, that is, the derivation of the best local priorities from a pairwise comparison matrix or a group of pairwise comparison matrices [63].

For criterion $\mathrm{K}_{1}$ :

$$
\begin{gathered}
A_{1}=\left[\begin{array}{ccc}
1 & 3 & 7 \\
\frac{1}{3} & 1 & 5 \\
\frac{1}{7} & \frac{1}{5} & 1
\end{array}\right] \\
\widetilde{\omega 1}=\sqrt[3]{1 \times 3 \times 7}=2.7582
\end{gathered}
$$

$$
\widetilde{\omega 2}=\sqrt[3]{\frac{1}{3} \times 1 \times 5}=1.1853 \quad \mathrm{~S}=2.7582+1.1853+0.3067=4.2502
$$

$$
\widetilde{\omega 3}=\sqrt[3]{\frac{1}{7} \times \frac{1}{5} \times 1}=0.3067
$$

$$
\omega_{1}=\frac{2.7582}{4.2502}=0.64895, \quad \omega_{2}=\frac{1.1853}{4.2502}=0.27888, \quad \omega_{3}=\frac{0.3067}{4.2502}=0.07216
$$

Sum of Columns:

$$
\begin{gathered}
\mathrm{S}_{1}=1+\frac{1}{3}+\frac{1}{7}=\frac{31}{21}, \quad \mathrm{~S}_{2}=3+1+\frac{1}{5}=\frac{21}{5}, \quad \mathrm{~S}_{3}=7+5+1=13 \\
\lambda_{\max }=\frac{31}{21} \times 0.64895+\frac{21}{5} \times 0.27888+13 \times 0.07216=3.0667
\end{gathered}
$$

The validation is made based on the " $\lambda$ max", a parameter introduced by Jayant [54]. For matrix $\mathrm{A}_{1}$, the consistency index is presented as follows:

$$
\mathrm{CI}=\frac{\lambda \max -n}{n-1}=0.0334
$$

The consistency coefficient is determined based on the following formula:

$$
\mathrm{RC}=\frac{C I}{R I(n)}
$$

For the evaluation of the random consistency index (RI), we refer to Saaty [61]. Regarding the random consistency index, Saaty [37] makes clear that "The CI of a matrix of comparisons is given by $\mathrm{CI}=(\lambda \max -n) /(n-1)$. The consistency ratio $(C R)$ is obtained by comparing the $\mathrm{CI}$ with appropriate one of the following set of numbers, each of which is an average random consistency index (RI) derived from a sample of size 500, of a randomly generated reciprocal matrix using the scale $1 / 9,1 / 8 \ldots, 1, \ldots 8,9$ to see if it is about 0.10 or less. If it is not less than 0.10 study the problem and revise the judgments." Saaty [61] 
has determined the values of the RI based on the number of evaluated criteria, as reflected in Table 2.

Table 2. The values of the random consistency index (RI).

\begin{tabular}{|c|c|c|c|c|c|c|c|c|c|c|}
\hline $\mathbf{N}$ & 1 & 2 & 3 & 4 & 5 & 6 & 7 & 8 & 9 & 10 \\
\hline RI & 0 & 0 & 0.58 & 0.9 & 1.12 & 1.24 & 1.32 & 1.41 & 1.45 & 1.49 \\
\hline
\end{tabular}

"RC", a quantitative expression of tolerance, is defined by Saaty, which for this matrix $\left(\mathrm{A}_{1}\right)$ turns out to be as follows:

$$
\begin{gathered}
\operatorname{RC}\left(A_{1}\right)=\frac{0.0336}{0.58}=0.05 \text { ose } 5 \% \\
\operatorname{RC}\left(A_{1}\right)<10 \%
\end{gathered}
$$

Various researchers, such as Cox et al. [64] and Soma [65], referring to Saaty, agree that, in general consistency ratios are acceptable up to the limit of 0.10 but there are other scholars offering a limit up to 0.20 .

This indicates that matrix $\mathrm{A}_{1}$ has a good consistency coefficient and can be evaluated at the same time. For this $\omega_{1}, \omega_{2}$ and $\omega_{3}$ represent the weights of alternatives $M_{1}, M_{2}$ and $\mathrm{M}_{3}$. It is important that the application of the AHP method be preceded by a calculation of the weight of every level in order to determine the global priorities by aggregating the local priorities [66].

Referring to criterion $\mathrm{K}_{2}$ :

$\checkmark$ Local weights regarding criterion 2

For this, a matrix of comparisons of mutual importance for the $\mathrm{K}_{2}$ criterion is constructed. The empirical resemblance between proximity matrices is determined by their comparison. They are named as a practical tool [67].

$$
\begin{gathered}
\mathrm{A}_{2}=\left[\begin{array}{ccc}
1 & 2 & 5 \\
\frac{1}{2} & 1 & 4 \\
\frac{1}{5} & \frac{1}{4} & 1
\end{array}\right] \\
\widetilde{\omega 1}=\sqrt[3]{1 \times 2 \times 5}=2.155 \\
\widetilde{\omega 2}=\sqrt[3]{\frac{1}{2} \times 1 \times 4}=1.254 \quad \mathrm{~S}=2.155+1.254+0.365=3.774 \\
\widetilde{\omega 3}=\sqrt[3]{\frac{1}{5} \times \frac{1}{4} \times 1}=0.365 \\
\omega_{1}=\frac{2.155}{3.774}=0.5710, \quad \omega_{2}=\frac{1.254}{3.774}=0.3323, \quad \omega_{3}=\frac{0.365}{3.774}=0.0967
\end{gathered}
$$

Sum of columns:

$$
\begin{gathered}
\mathrm{S}_{1}=1+\frac{1}{2}+\frac{1}{5}=1.7, \quad \mathrm{~S}_{2}=2+1+\frac{1}{4}=\frac{21}{5}, \quad \mathrm{~S}_{3}=5+4+1=10 \\
\lambda_{\max }=1.7 \times 0.5710+3.25 \times 0.3323+10 \times 0.0967=3.0177 \\
\mathrm{CI}=\frac{3.0177-3}{2}=0.0088 \\
\mathrm{RC}\left(\mathrm{A}_{2}\right)=\frac{0.0088}{0.58}=0.015 \text { or } 1.5 \% \\
\operatorname{RC}\left(\mathrm{A}_{2}\right)<10 \%
\end{gathered}
$$


The inequality indicates that consistency for the $A_{2}$ matrix is a good one. Thus $\omega(0$. $5710,0.3323$ and 0.0967$)$ represents the weights of alternatives $M_{1}, M_{2}$ and $M_{3}$ according to the $\mathrm{K}_{2}$ criterion.

$\checkmark$ Local weights regarding criterion

$\checkmark$ Matrix of alternative comparisons for criterion $\mathrm{K}_{3}$ :

$$
\begin{gathered}
\mathrm{A}_{3}=\left[\begin{array}{lll}
1 & 4 & 6 \\
\frac{1}{4} & 1 & 5 \\
\frac{1}{6} & \frac{1}{5} & 1
\end{array}\right] \\
\widetilde{\omega 1}=\sqrt[3]{1 \times 4 \times 6}=2.920 \\
\widetilde{\omega 2}=\sqrt[3]{\frac{1}{4} \times 1 \times 5}=1.077 \quad \mathrm{~S}=2.920+1.077+0.309=4.306 \\
\widetilde{\omega 3}=\sqrt[3]{\frac{1}{6} \times \frac{1}{5} \times 1}=0.309 \\
\omega_{1}=\frac{2.920}{4.306}=0.6781, \quad \omega_{2}=\frac{1.077}{4.306}=0.2501, \quad \omega_{3}=\frac{0.309}{4.306}=0.0712
\end{gathered}
$$

Sum of columns:

$$
\begin{gathered}
\mathrm{S}_{1}=1+\frac{1}{4}+\frac{1}{6}=\frac{17}{12}, \quad \mathrm{~S}_{2}=4+1+\frac{1}{5}=\frac{26}{5}, \quad \mathrm{~S}_{3}=6+5+1=12 \\
\lambda_{\max }=0.6781 \times \frac{17}{12}+0.2501 \times \frac{26}{5}+0.0712 \times 12=3.116 \\
\mathrm{CI}=\frac{3.116-3}{2}=0.58 \\
\mathrm{RC}\left(\mathrm{A}_{3}\right)=\frac{0.58}{0.58}=0.1 \text { or } 10 \%
\end{gathered}
$$

The consistency of the $\mathrm{A}_{3}$ matrix also turns out to be good. Therefore, $\omega$ values $(0.6781,0.2501$ and 0.0712$)$ are the weights of alternatives $M_{1}, M_{2}$ and $M_{3}$ according to the $\mathrm{K}_{3}$ criterion.

Evaluation of the weights of the criteria that the decision maker has chosen:

The matrix of comparisons of the set of criteria:

$$
\begin{gathered}
\mathrm{A}_{\mathrm{c}}=\left[\begin{array}{ccc}
1 & 3 & 6 \\
\frac{1}{3} & 1 & 4 \\
\frac{1}{6} & \frac{1}{4} & 1
\end{array}\right] \\
\widetilde{\omega 1}=\sqrt[3]{1 \times 3 \times 6}=2.617 \\
\widetilde{\omega 2}=\sqrt[3]{\frac{1}{3} \times 1 \times 4}=1.1 \quad \mathrm{~S}=2.617+1.1+0.35=4.067 \\
\widetilde{\omega 3}=\sqrt[3]{\frac{1}{6} \times \frac{1}{4} \times 1}=0.35 \quad \\
\omega_{1}=\frac{2.617}{4.067}=0.643, \quad \omega_{2}=\frac{1.1}{4.067}=0.2704, \quad \omega_{3}=\frac{0.35}{4.067}=0.086
\end{gathered}
$$

Sum of Columns:

$$
\mathrm{S}_{1}=1+\frac{1}{3}+\frac{1}{6}=\frac{9}{6}, \quad \mathrm{~S}_{2}=3+1+\frac{1}{4}=\frac{17}{4}, \quad \mathrm{~S}_{3}=6+4+1=11
$$




$$
\begin{gathered}
\lambda_{\max }=\frac{9}{6} \times 0.643+\frac{17}{4} \times 0.2704+11 \times 0.086=3.0602 \\
\mathrm{CI}=\frac{3.0602-3}{2}=0.0301 \\
\mathrm{RC}\left(\mathrm{A}_{\mathrm{c}}\right)=\frac{0.0301}{0.58}=0.051 \text { or } 5.1 \%
\end{gathered}
$$

According to the results of the calculations, the matrix Ac has a good consistency coefficient. Thus, $\omega(\mathrm{c})=(0.643,0.2704,0.0860)$, which is the vector of the weights of the three criteria considered.

Assessing the global weights for each alternative:

Based on the weights of the alternatives above, the results show that:

$$
\omega *=\left[\begin{array}{lll}
0.6490 & 0.5710 & 0.6781 \\
0.2789 & 0.3323 & 0.2501 \\
0.0722 & 0.0967 & 0.0712
\end{array}\right] \times\left[\begin{array}{l}
0.6430 \\
0.2704 \\
0.0860
\end{array}\right]=\left[\begin{array}{l}
0.6301 \\
0.0215 \\
0.0791
\end{array}\right]
$$

The largest value of weight is $\omega_{1}=0.6301$. This belongs to the alternative beer "S . . 1". As one of the competitive alternative beers, "S ... 1" with highest weight 0.6301 should be recommended by the company to its clients. Thus, the decision to be made by the managers of S. \& Co has been established on the basis of a scientific method guided by economic logic. Therefore, the launch of this beer will ensure the stability and good performance of the company in the market and thus make the business more competitive.

On top of that, AHP-based decision making minimizes human error and reduces the economic costs of the decision. Human error derives from the subjectivity of its assessments. It is a problem that was developed by Labib [68]. Decision making, especially group decision making, is a difficult activity because of a heterogeneous spread of expertise. Therefore, Dey et al. [69] have advanced AHP as a means of overcoming potential bias.

From the above, we can conclude that S. \& Co, using the scientific methods embodied in the Analytic Hierarchy Process (AHP) in its decision making, can claim that its performance will be much improved. S. \& Co aims to achieve objectives relating to production cost, taste and consistency for three beer alternatives "S . . 1" $\left(\mathrm{M}_{1}\right)$, "S . . 2" $\left(\mathrm{M}_{2}\right)$ and "S .. 3" $\left(\mathrm{M}_{3}\right)$. The decision maker can use a branch of mathematics, combinatorics, to generate a large number of alternatives (N!). According to Hart [70], combinatorics is the mathematics of counting. It is concerned with problems that involve a finite number of elements (discrete sets) on which different operations can be performed. Hart [70] has stressed that "We are usually interested in a combinatorial configuration or composition of the result of some of these operations, and we attempt to answer the following question: Does a specific combinatorial configuration exist?"

Based on the above, finding the specific combination is difficult, requires a lot of time and increases decision uncertainty. Using AHP provides the best alternative in the short term. According to Chukwudi et al. [71], "The selection of the unit of analysis is tightly coupled with the research question under consideration. ... the unit of analysis is most likely to be the relationship stated in the hypothesis".

AHP, as an analytical method, considers the importance of the criteria through an evaluation of their respective weights. In this way, it is possible to determine the criteria that dominate the decision. This is an advantage of the AHP [27]. The advantages of AHP has increased the use of this method in decision making by businesses operating in different sectors [72].

\section{Discussion and Conclusions}

From a theoretical point of view, decision making in general is a wide and permanent part of managerial activity with an impact on business performance. The AHP decisionmaking method has been esteemed by many scholars as a method that improves the decision making quality. We can conclude that the AHP is an efficient method for multi- 
criteria decision making. In this context, the AHP seems to be one of the most suitable methods for solving complex business problems. Decision making considers numerous and different criteria. They are strategic factors that condition business success in complex market situations. The AHP realizes a comparative analysis of the criteria that impact decision making. In this manner, it determines the best available alternative.

The paper has discussed the evidence for the benefits to business that can be obtained using an analytical method of decision making based on the AHP. The analysis of this paper proves how important the AHP is for reasoned decision making. From a theoretical description of the advantages of the AHP and comparing its use in an actual situation with decision making processes in which intuitive methods predominate, the AHP appears can be seen to constitute a new approach that ensures quick, easy and rational decision making. Therefore, it can be recommended to managers as a simple method for making decisions that is accessible and feasible.

This paper has proved how important the AHP is for reasoned decision making and demonstrated the advantages of the method. It provides new insights into the application of scientific methods in business decision making in the countries of the Western Balkans region. The use of the AHP method in case of the S. \& Co company can serve as a positive example or as a manual for the practical application of the method for other businesses as well. From this point of view, the article brings an additional contribution to the economic literature in the national language for the countries of the region.

Author Contributions: All authors have contributed to the study and writing of this research. I.C. and D.K. conceived the general idea of the research; T.I. analyzed the data and drew the main conclusions and proposals. All authors have read and agreed to the published version of the manuscript.

Funding: The publication of this paper is made possible by the funds of the Banat's University of Agricultural Sciences and Veterinary Medicine from Timisoara and the Research Institute for Biosecurity and Bioengineering Timisoara.

Institutional Review Board Statement: Not applicable.

Informed Consent Statement: Informed consent was obtained from the participants involved in this study.

Data Availability Statement: The data presented in this study/paper are available upon request from the principal author.

Conflicts of Interest: The authors declare no conflict of interest. The funding institute had no role in the design of the study; in the collection, analyses, or interpretation of data; in the writing of the manuscript, or in the decision to publish the results.

\section{References}

1. Anderson, B.F. The Three Secrets of Wise Decision Making; Single Reef Press: Portland, OR, USA, 2002.

2. Covina, J.G.; Slevin, D.P.; Heeley, M.B. Strategic decision making in an intuitive vs. technocratic mode: Structural and environmental considerations. J. Bus. Res. 2001, 52, 51-67. [CrossRef]

3. Dane, E.; Rockmann, K.W.; Pratt, M.G. When should I trust my gut? Linking domain expertise to intuitive decision-making effectiveness. In Organizational Behavior and Human Decision Processes; Elsevier: Amsterdam, The Netherlands, 2021.

4. Nygren Th, E.; White, R.J. Assessing individual differences in decision making styles: Analytical vs intuitive. Proc. Hum. Factors Ergon. Soc. Annu. Meet. 2002, 46, 953-957. [CrossRef]

5. Kral, P.; Valjaskova, V.; Janoskova, K. Quantitative approach to project portfolio management: Proposal for Slovak companies. Oeconomia Copernic. 2019, 10, 797-814. [CrossRef]

6. Kliestik, T.; Belas, J.; Valaskova, K.; Nica, E.; Durana, P. Earnings management in V4 countries: The evidence of earnings smoothing and inflating. Econ. Res. 2021, 34, 1452-1470. [CrossRef]

7. Valaskova, K.; Adamko, P.; Frajtova-Michalikova, K.; Macek, J. Quo Vadis earnings management? Analysis of manipulation determinants in Central European environment. Oeconomia Copernic. 2021, 12, 631-669. [CrossRef]

8. Rosanas, J.M. Decision-Making in an Organizational Context. Beyond Economic Criteria; Springer: Berlin, Germany, 2013.

9. Elbanna, S.; Child, J.; Dayan, M. A Model of Antecedents and Consequences of Intuition in Strategic Decision-making Evidence from Egypt. Long Range Plan. 2013, 46, 149-176. [CrossRef]

10. Shahsavarani, A.M.; Abadi, E.A.M. The bases, principles and methods of decision making. Int. J. Med. Rev. 2015, 2, $214-225$.

11. Mullen, J.D.; Roth, B.M. Decision-Making: Its Logic and Practice; Rowman \& Littlefield Publishers: Lanham, MD, USA, 1991. 
12. Hammond, J.S.; Keeney, R.L.; Raiffa, H. Smart Chooces, A Practical Guide to Making Better Life Decisions; Harvard Business School Press: Boston, MA, USA, 1999; pp. 27-35.

13. Pereyra-Rojas, M.; Mu, E. Practical Decision Making: An Introduction to the Analytic Hierarchy Process (AHP) Using Super Decisions V2; Springer: Berlin, Germany, 2017.

14. Wood, N.; Jones, J.; Schelling, J.; Schmidtlein, N. Tsunami vertical-evacuation planning in the U.S. Pacific Northwest as a geospatial, multi-criteria decision problem. Int. J. Disaster Risk Reduct. 2014, 9, 68-83. [CrossRef]

15. Chuu, S.J. An investment evaluation of supply chain RFID technologies: A group decision making model with multiple information sources. Knowl.-Based Syst. 2014, 66, 210-220. [CrossRef]

16. Garvin, D.A.; Roberto, M.A. What you don't know about making decisions. Harv. Bus. Rev. 2001, 79, 108-119. [CrossRef]

17. Cohen, M.D.; March, J.G.; Olsen, J.P. A garbage can model of organizational choice. Adm. Sci. Q. 1972, 17, 1-25. [CrossRef]

18. McFarland, D. and Gomez, C. J. Organizational Analysis; Stanford University Press: Palo Alto, CA, USA, 2013.

19. Nobuyuki, I. Garbage Can Mode: Mysteries in the Original Simulation Model. Ann. Bus. Adm. Sci. 2015, 14, 15-34.

20. Simon, H.A. Administrative Behavior, 1st ed.; Free Press: New York, NY, USA, 1947.

21. Canco, I. Identification of the impact of organizational culture on the decision-making method. Eur. J. Econ. Manag. Sci. 2016, 2, 27-32. [CrossRef]

22. Sinclair, M.; Ashkanasy, N.M. Intuition: Myth or a Decision-making Tool? Manag. Learn. 2005, 36, 353-370. [CrossRef]

23. Salas, E.; Rosen, M.A.; DiazGranados, D. Expertise-Based Intuition and Decision Making in Organizations. J. Manag. 2010, 36, 941-973. [CrossRef]

24. Figuena, J.; Greco, S.; Ehrgott, M. (Eds.) Multiple Criteria Decision Analysis, State of the Art Surveys; Springer: Berlin, Germany, 2005.

25. Michalski, D.J.; Bearman, C. Factors affecting of decision making of pilots who fly in Outback Australia. Saf. Sci. 2014, 68, $288-293$. [CrossRef]

26. Singh, B. Analytical Hierarchical Process (AHP) And Fuzzy AHP Applications-A Review Paper. Int. J. Pharm. Technol. 2016, 8 , 4925-4946.

27. Emrouznejad, A.; Marra, M. The state of the art development of AHP (1979-2017): A literature review with a social network analysis. Int. J. Prod. Res. 2017, 55, 6653-6675. [CrossRef]

28. Bodin, L.; Gass, S.I. On teaching the analytic hierarchy process. Comput. Oper. Res. 2003, 30, 1487-1497. [CrossRef]

29. Vaidya, O.S.; Kumar, S. Analytic Hierarchy Process, an overview of applications. Eur. J. Oper. Res. 2006, 169, 1-29. [CrossRef]

30. Dozic, S.; Kalic, M. An AHP Approach to Aircraft Selection Process. Transp. Res. Procedia 2014, 3, 165-174. [CrossRef]

31. Salgado, E.; Salomon, V.A.P.; Mello, C. Analytic hierarchy prioritisation of new product development activities for electronics manufacturing. Int. J. Prod. Res. 2012, 50, 4860-4866. [CrossRef]

32. Karthikeyan, R.; Venkatesan, K.G.S.; Chandrasekar, A. A Comparison of Strengths and Weaknesses for Analytical Hierarchy Process. J. Chem. Pharm. Sci. 2016, 9, S-12-S-15.

33. Munier, N.; Hontoria, E. Uses and Limitations of the AHP Method. A Non-Mathematical and Rational Analysis. In Management for Professionals; Springer: Berlin, Germany, 2021.

34. Jiménez, B.; Barrios, J.; Mendez, J.; Diaz, J. Sustainable management of sludge in developing countries. Water Sci. Technol. 2004, 49, 251-258. [CrossRef] [PubMed]

35. Song, B.; Kang, S. A method of assigning weights using a ranking and nonhierarchy comparison. Adv. Decis. Sci. 2016, 2016, 8963214. [CrossRef]

36. Kazibudzki, P.T. On some discoveries in the field of scientific methods for management within the concept of analytic hierarchy process. Int. J. Bus. Manag. 2013, 8, 22-30. [CrossRef]

37. Saaty, R.W. The AHP—what it is and how it is used. Math. Model. 1987, 9, 161-176. [CrossRef]

38. Akcan, S.; Güldeş, M. Integrated Multicriteria Decision-Making Methods to Solve Supplier Selection Problem: A Case Study in a Hospital. J. Healthc. Eng. 2019, 2019, 5614892. [CrossRef]

39. Russo R de, F.S.M.; Camanho, R. Criteria in AHP: A systematic Review of Literature. Proceedia Comput. Sci. 2015, 55, 1123-1132. [CrossRef]

40. Saaty, T.L. Decision making with the analytic hierarchy process. Int. J. Serv. Sci. 2008, 1, 83-98. [CrossRef]

41. Belton, V. A comparison of the analytic hierarchy process and a simple multi-attribute value function. Eur. J. Oper. Res. 1986, 26, 7-21. [CrossRef]

42. Yin, R.K. Case Study Research: Design and Methods, 4th ed.; Sage Publications: Thousand Oaks, CA, USA, 2009 ; pp. 93-101.

43. Sipahi, S.; Timor, M. The analytic hierarchy process and analytic network process: An overview of applications. In Management Decision; Emerald Publishing: Bradford, UK, 2010.

44. Bhushan, N.; Rai, K. Strategic Decision Making-Applying the Analytic Hierarchy Process; Springer Science \& Business Media: Berlin, Germany, 2007.

45. Gerring, J. Case Study Research: Principles and Practices; Cambridge University Press: Cambridge, UK, 2007.

46. Yin, R.K. Validity and generalization in future case study evaluations. Evaluation 2013, 12, 219-245. [CrossRef]

47. Verschuren, P. Case study as a research strategy: Some ambiguities and opportunities. Int. J. Soc. Res. Methodol. 2003, 6, 121-139. [CrossRef]

48. Murphy, M. What are the benefits and drawbacks of case study research? In Research and Education; Routledge: Abingdon, UK; New York, NY, USA, 2014; pp. 80-82. 
49. Dul, J.; Hak, T. Case Study Methodology in Business Research; Butterworth-Heinemann: Oxford, UK, 2008.

50. Longaray, A.A.; Goisa, D.J.; Munhoza, R.P. Proposal for using AHP Method to Evaluate the Quality of Services Provided by Outsourced Companies. Proceedia Comput. Sci. 2015, 55, 715-724. [CrossRef]

51. Garuti, G.; Salomon, V.A.P. Compatibility indices between priority vectors. Int. J. Anal. Hierarcy Process. 2012, 4, 152-160. [CrossRef]

52. Patil, V.D.; Sankhua, R.N.; Jain, R.K. Analytical Hierarchy Process Framework for Residential Landuse Suitability using MultiCriteria Decision Analysis. Int. J. Eng. Res. Appl. 2012, 2, 1306-1311.

53. Sabaei, D.; Erkoyuncu, J.; Roy, R. A review of multi-criteria decision making methods for enhanced maintenance delivery. Procedia CIRP 2015, 37, 30-35. [CrossRef]

54. Jayant, A. An Analytical Hierarchy Process (AHP) Based Approach for Supplier Selection: An Automotive Industry Case Study. Int. J. Bus. Insights Transform. 2018, 11, 36-45.

55. Kahraman, C.; Kaya, I. A Fuzzy Multicriteria Methodology for Selection Among Energy Alternatives. Expert Syst. Appl. 2010, 37, 6270-6281. [CrossRef]

56. Emrouznejad, A.; Marra, M. Ordered Weighted Averaging Operators 1988-2014: A Citation-based Literature Survey. Int. J. Intell. Syst. 2014, 29, 994-1014. [CrossRef]

57. Saaty, T.L. How to make a decision: The Analytic Hierarchy Process. Eur. J. Oper. Res. 1990, 48, 9-26. [CrossRef]

58. Koç, E.; Burhan, H.A. An Analytic Hierarchy Process (AHP) Approach to a Real World Supplier Selection Problem: A Case Studt of Carglass Turkey. Glob. Bus. Manag. Res. 2014, 6, 1-14.

59. Saaty, T. A scaling method for priorities in hierarchical structures. J. Math. Psychol. 1977, 15, 234-281. [CrossRef]

60. Cristobal, S.; Ramon, J. Multi Criteria Analysis in the Renewable Energy Industry; Springer Science \& Business Media: Berlin, Germany, 2012.

61. Saaty, T.L. Theory and Applications of the Analytic Network Process: Decision Making with Benefits, Opportunities, Costs, and Risks; RWS Publications: Pittsburgh, PA, USA, 2005.

62. Ezzat, E.M.A.; Hamoud, S.H. Analytic hierarchy process as module for productivity evaluation and decision-making of the operation theatre. Avicenna J. Med. 2016, 6, 3. [PubMed]

63. Wang, Y.M.; Chin, K.S. A New Data Envelopment Analysis Method for Priority Determination and Group Decision Making in the Analytic Hierarchy Process. Eur. J. Oper. Res. 2009, 195, 239-250. [CrossRef]

64. Cox, A.M.; Alwang, J.; Johnson, T.G. Local preferences for economic development outcomes: Analytical hierarchy procedure, Growth and change Summer. Growth Chang. 2000, 31, 341-366. [CrossRef]

65. Soma, K. How to involve stakeholders in fisheries management- a country case study in Trinidad and Tobago. Mar. Policy 2003, 27, 47-58. [CrossRef]

66. Emrouznejad, A.; Ho, W. Fuzzy Analytic Hierarchy Process; CRC Press: Boca Raton, FL, USA, 2017.

67. Schneider, W.J.; Borlund, P. Matrix comparison, Part 1: Motivation and important issues for measuring the resemblance between proximity measures or ordination results. J. Am. Soc. Inf. Sci. Technol. 2007, 58, 1586-1595. [CrossRef]

68. Labib, A.W. A Supplier Selection Model: A Comparison of Fuzzy Logic and the Analytic Hierarchy Process. Int. J. Prod. Res. 2011, 49, 6287-6299. [CrossRef]

69. Dey, B.; Bairagi, B.; Sarkar, B.; Sanyal, K.S. Group heterogeneity in multi member decision making model with an application to warehouse location selection in a supply chain. Comput. Ind. Eng. 2016, 105, 99-109. [CrossRef]

70. Hart, S. Games in Extensive and Strategic Forms. In Handbook of Game Theory; Elsevier: Amsterdam, The Netherlands, 1992; Volume 1.

71. Chukwudi, I.; Zhang, M.; Gable, G. Extensive Theory Testing Using Case. In Proceedings of the 40th International Conference on Information Systems, ICIS, Munich, Germany, 15-18 December 2019.

72. Cheever, M.A.; Allison, J.P.; Ferris, A.S.; Finn, O.J.; Hastings, B.M.; Hecht, T.T.; Mellman, I.; Prindiville, S.A.; Viner, J.L.; Weiner, L.M.; et al. The Prioritization of Cancer Antigens: A National Cancer Institute Pilot Project for the Acceleration of Translational Research. Clin. Cancer Res. 2009, 15, 5323-5337. [CrossRef] [PubMed] 